\title{
Assessment of tidal breathing parameters in infants with cystic fibrosis
}

\author{
S.C. Ranganathan*, I. Goetz*,\#, A-F. Hoo*,\#, S. Lum*,\#, R. Castle*, J. Stocks* \\ and the London Collaborative Cystic Fibrosis Group*
}

Assessment of tidal breathing parameters in infants with cystic fibrosis. S.C. Ranganathan, I. Goetz, A-F. Hoo, S. Lum, R. Castle, J. Stocks, London Collaborative Cystic Fibrosis Group. (C) ERS Journals Ltd 2003.

ABSTRACT: Simple methods are needed to assess lung function in infants with cystic fibrosis (CF). This study determined the relationship between simple measurements obtained from tidal breathing with those from more complicated forced expiratory manoeuvres.

Healthy infants and infants with $\mathrm{CF}$ were recruited from two maternity units and five specialist CF hospitals, respectively. Respiratory rate, tidal volume, minute ventilation and the tidal breathing ratio (TPTEF:TE) were measured in sedated infants and compared with forced expiratory volume in 0.4 seconds (FEV0.4) measured by the raised volume technique.

Altogether, 95 healthy infants and 47 infants with $\mathrm{CF}$ of similar age, sex, ethnicity and proportion exposed to maternal smoking were recruited. There was no difference in TPTEF:TE and tidal volume between healthy infants and those with CF. Minute ventilation was significantly greater in infants with $\mathrm{CF}$ due to a mean $(95 \%$ confidence interval) increase in respiratory rate of $5.8(3.2-8.4) \mathrm{min}^{-1}$. Thirteen $(28 \%)$ infants with $\mathrm{CF}$ had a respiratory rate elevated by $>2$ SD. However, no association between respiratory rate and FEV0.4 could be identified.

Tidal breathing ratio was not useful in identifying diminished airway function in infants with cystic fibrosis. An elevated respiratory rate may be due in part to ventilation heterogeneity but is poorly predictive of diminished airway function measured by forced expiration.

Eur Respir J 2003; 22: 761-766.
*Portex Anaesthesia, Intensive Therapy and Respiratory Medicine Unit, Institute of Child Health, and ${ }^{\#}$ Neonatal Unit, Homerton University Hospital, London, UK.

Correspondence: S. Ranganathan, Portex Unit, 6th Floor, Cardiac Wing, Institute of Child Health, 30 Guilford Street, London, WC1N $1 \mathrm{EH}$ UK.

Fax: 442078298634

E-mail: drsarath@clara.net

Keywords: Cystic fibrosis, early intervention, forced expiration, infant, respiratory function, tidal breathing

Received: March 52003

Accepted after revision: June 112003

This work was supported by the Cystic Fibrosis Trust, the Foundation for the Study of Sudden Infant Death, the Dunhill Medical Trust and Portex Ltd. Research at the Institute of Child Health benefits from research and development funding received from the National Health Service executives.
Increasing awareness that both inflammatory and functional changes in the lungs of subjects with cystic fibrosis $(\mathrm{CF})$ occur much earlier than previously recognised [1], together with the introduction of neonatal screening and the potential opportunities for early therapeutic interventions, have emphasised the need for simple methods to assess lung function during early life. Ideally, such methods should be applicable to non-sedated infants, thereby facilitating widespread applications and repeat measurements at regular intervals during the critical period of lung growth and development in the first 2 yrs of life.

The most commonly used techniques for assessing airway function in infants with $\mathrm{CF}$ have been either partial or full forced expiratory manoeuvres [2]. However, the need for complex equipment and highly trained personnel has generally limited application of these techniques to specialised centres. Following the publication of the initial results from the Tucson study, which suggested that time to reach peak tidal expiratory flow (TPTEF) in relation to total expiratory time (TE; the tidal breathing ratio (TPTEF:TE)) was diminished in symptom-free male infants who subsequently wheezed [3, 4], several studies have been undertaken to examine tidal flow patterns in both healthy infants and those with airway disease [5-9]. Recording of tidal breathing is technically simple and potentially allows measurements to be undertaken at the patient's bedside during natural quiet sleep $[5,10]$. Consequently, despite ongoing controversy regarding their interpretation $[11,12]$, the evaluation of TPTEF:TE and other related parameters has continued to attract interest.
The aim of the present study was to determine the relationship between tidal breathing parameters and forced expiratory volume in $0.4 \mathrm{~s}$ (FEV0.4) in infants newly diagnosed with CF when compared with a prospectively recruited population of healthy infants.

\section{Methods}

Subjects

Infants and young children newly diagnosed with $\mathrm{CF}$ by sweat test and/or by positive genotype for CF mutations [13] were recruited, as described in detail previously [14, 15], from five specialist centres in London where neonatal screening is not routinely undertaken. Subjects were eligible if aged $<24$ months at diagnosis and free from additional congenital or acquired cardio-respiratory or neurological abnormalities.

Healthy infants born at the Homerton or University College Hospitals in London were recruited as part of an ongoing epidemiological study [16]. Subjects with a history of respiratory illness requiring hospitalisation, congenital abnormalities, requirement for assisted ventilation in the neonatal period or born prematurely ( $<36$ weeks) were ineligible.

Parents of both healthy infants and those with $\mathrm{CF}$ gave informed written consent. The study was approved by the North Thames Multicentre Research Ethics Committee and the Local Research Ethics Committees of the participating hospitals. 


\section{Measurements of lung function}

All infants were tested when well and clinically free from an upper respiratory tract infection for $\geqslant 3$ weeks. On the day of testing, infants were weighed and crown-heel length measured. Weight and length SD scores were calculated using Child Growth Foundation algorithms [17]. Exposure to maternal smoking pre and postnatally was assessed from maternal report and current smoking habits confirmed by maternal salivary cotinine [18]. All infants were studied in the supine position, following sedation with an oral or rectal dose of $60-100 \mathrm{mg} \cdot \mathrm{kg}^{-1}$ of chloral hydrate or an equivalent dose of triclofos sodium. The shoulders of the infant were supported with a roll so that the neck rested in slight extension. Once in quiet sleep a transparent facemask (Rendell-Baker size 1 or 2; Rusch UK Ltd., High Wycombe, UK), the effective dead space (i.e. 50\% water displacement volume [19]) which was 7.5 and $10 \mathrm{~mL}$, respectively, was positioned over the infant's mouth and nose, and a leak-free seal created using therapeutic putty [20]. Airflow was measured with a heated pneumotachometer (for infants $\leqslant 5 \mathrm{~kg}$ : model 3500 , dead space $6.8 \mathrm{~mL}$, linearity $0-35 \mathrm{~L} \cdot \mathrm{min}^{-1}$; for infants $>5 \mathrm{~kg}$ : model 3700 , dead space $13.9 \mathrm{~mL}$, linearity 0-160 L· $\mathrm{min}^{-1}$, Hans Rudolph, Kansas City, MO, USA) and the signal digitally integrated to obtain volume. The infant was studied in quiet sleep determined behaviourally by the presence of stable posture, infrequent startles and regular breathing pattern, and by the absence of rapid eye movement or frequent sucking movements [21]. Tidal breathing parameters were calculated from a minimum of 20 breaths, recorded during at least two periods of quiet regular breathing [6].

Measurements of FEV0.4 were performed as described in detail previously using the raised volume technique at a lung inflation pressure of $3 \mathrm{kPa}[16,22]$. Manoeuvres were repeated until at least two acceptable and repeatable flow/volume curves were obtained $[16,22]$.

\section{Calculation of results}

At the end of the study, data were exported as ASCII files for analysis using previously validated software [23]. Tidal breathing parameters, including respiratory rate (RR), tidal volume $(V T)$, minute ventilation (MV), and time to TPTEF as TPTEF:TE were calculated during tidal breathing. FEV0.4 was reported from the "best" flow/volume curve (defined as the technically acceptable manoeuvre with the highest sum of forced vital capacity and FEV0.4) [16, 22, 24]. Results were expressed both in absolute terms and as SD scores, based on measurements obtained in the healthy infants.

\section{Statistical analysis}

Unpaired t-tests were used to compare groups of normally distributed data and for non-normally distributed data the Mann-Whitney U-test was used. Categorical variables were compared with Chi-squared tests. Associations between FEV0.4, the various tidal breathing parameters and CF were examined using multiple linear regression after allowing for differences in age, sex, length, weight and exposure to maternal smoking. Normality plots were used to verify that assumptions of normality were met. Pearson's correlation was used to assess relationships between normally distributed variables.

\section{Power}

The authors estimated that body size, sex and exposure to maternal smoking might account for $40-80 \%$ of the variability in the selected outcome measures. Were an additional $10 \%$ of this variability due to $\mathrm{CF}$, a sample of 90 controls and $30 \mathrm{CF}$ patients would be sufficient to detect this with $\geqslant 80 \%$ power at the $5 \%$ significance level [25].

\section{Results}

Lung function measurements were attempted in 47 infants with CF, details of whom have been published previously [15]. Infants with $\mathrm{CF}$ were diagnosed at a median (range) corrected age of 30 (6-93) weeks and tested within an interval from diagnosis of $12(0-38)$ weeks. Details of the subjects are summarised in table 1. Background characteristics of the current control group of 95 infants were similar to those reported previously [15]. The groups were similar in the proportion that was male, White and exposed to maternal smoking. Infants with CF were of similar age when tested but were significantly lighter and shorter than the healthy infants.

\section{Lung function data}

Tidal breathing measurements were successful in all infants, while forced expiratory manoeuvres were successful in all healthy infants and all but five of those with CF. A median of 53 (range, 20-120) breaths was analysed in each subject for assessment of tidal breathing. Results for RR, $V \mathrm{~T}, \mathrm{MV}$ and TPTEF:TE are summarised in table 2, whilst $\mathrm{MV} \cdot \mathrm{kg}^{-1}$ and TPTEF:TE in relation to age and clinical status are shown in figure 1. RR and MV were significantly higher in those with $\mathrm{CF}$, as was $V \mathrm{~T}$ when related to body weight, but there was no

Table 1.-Details of the infants

Cystic fibrosis infants

\section{Subjects $n$}

Males \%

Whites \%

Maternal smoking \%

Gestational age weeks

Birth weight $\mathrm{kg}$

Birth weight SD score

Age at test weeks

Weight $\mathrm{kg}$

Weight SD score

Length $\mathrm{cm}$

Length SD score

Healthy infants

95

$50(53)$

$95(100)$

$27(28)$

$40.0(1.4)$

$3.36(0.42)$

$-0.25(0.78)$

$29.6(3-100)$

$8.00(2.05)$

$-0.04(0.95)$

$69.2(7.6)$

$0.69(0.96)$

Cystic fibrosis-healthy infants ${ }^{\#}$

Data are presented as mean (SD) unless otherwise stated. ${ }^{*}$ : difference $\left(95 \%\right.$ confidence interval); ${ }^{\circ}$ : median (range). ${ }^{*}: \mathrm{p}<0.05 ; * * *: \mathrm{p}<0.001$. 
Table 2.-Comparison of lung function results in infants with and without cystic fibrosis

\begin{tabular}{|c|c|c|c|}
\hline & Cystic fibrosis infants & Healthy infants & Cystic fibrosis-healthy infants \\
\hline Subjects n & 47 & 95 & \\
\hline Respiratory rate $\min ^{-1}$ & $42.9(10.5)$ & $35.2(7.3)$ & $7.7(4.3-11.1)^{* * * * *}$ \\
\hline$V \mathrm{~T} \mathrm{~mL}$ & $68.5(21.2)$ & $72.2(21.5)$ & $-3.7(-3.8-11.3)$ \\
\hline$V \mathrm{~T} \mathrm{~mL} \cdot \mathrm{kg}^{-1}$ & $10.1(1.6)$ & $9.0(1.3)$ & $1.1(0.5-1.6)^{* * *}$ \\
\hline $\mathrm{MV} \mathrm{mL} \cdot \mathrm{kg}^{-1}$ & $424(94.3)$ & $313(59.6)$ & $111(81-141)^{* * *}$ \\
\hline TPTEF:TE & $0.266(0.085)$ & $0.263(0.073)$ & $0.003(-0.024-0.031)$ \\
\hline $\mathrm{FEV} 0.4 \mathrm{~mL}$ & $159.6(58.0)^{4}$ & $226.0(69.2)$ & $-66.3(-90.4-42.1)^{* * *}$ \\
\hline FEV0.4 SD score & $-0.95(0.83)^{\bullet}$ & $0.01(0.99)$ & $-0.96(-1.3--0.61)^{* * *}$ \\
\hline
\end{tabular}

Data are presented as mean (SD) unless otherwise stated. $V \mathrm{~T}$ : tidal volume; MV: minute ventilation; TPTEF:TE: tidal breathing ratio; FEV0.4: forced expiratory volume in 0.4 seconds. ${ }^{*}$ : difference $\left(95 \%\right.$ confidence interval); ${ }^{\uparrow}: \mathrm{n}=42 ; *$ : $\mathrm{p}<0.05 ; * * *: \mathrm{p}<0.001$.

difference in absolute $V \mathrm{~T}$ or TPTEF:TE between the two groups.

After accounting for the effects of age, length, weight, sex and exposure to maternal smoking, RR and MV remained elevated in infants with CF by a mean of $5.8(95 \%$ confidence interval (CI) 3.2-8.4) $\mathrm{min}^{-1}$ and $0.60(0.46-0.74) \mathrm{L}$, respectively. By contrast, even when adjusted for these factors, there was no significant difference in $V \mathrm{~T}$ difference (CF-healthy) $(0.97(-2.4-4.3) \mathrm{mL}(\mathrm{p}=0.57))$. Thus, the elevated $\mathrm{MV}$ in infants with $\mathrm{CF}$ was due to an elevated $\mathrm{RR}$, rather than an increase in $V \mathrm{~T}$. Similarly, after adjustment for age and body size, there remained no difference in TPTEF:TE between infants with CF and controls (-0.005 (-0.036-0.025)). Neither sex nor exposure to maternal smoking had any significant influence on any of the tidal breathing parameters.

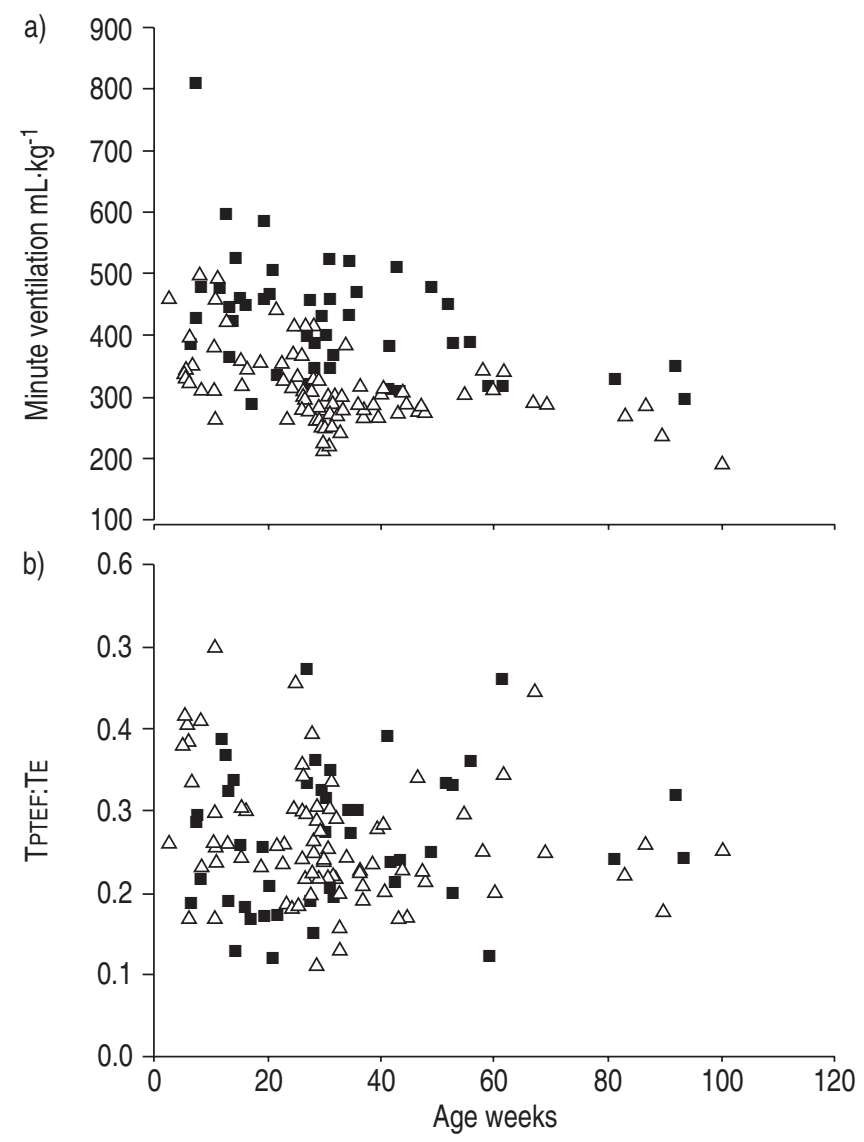

Fig. 1.-a) Minute ventilation per $\mathrm{kg}$ and $\mathrm{b}$ ) tidal breathing ratio (TPTEF:TE) plotted against age according to clinical status. $\mathbf{\square}$ : infants with cystic fibrosis; $\triangle$ : healthy infants.
As shown previously [14], after similar adjustment, FEV0.4 was significantly lower in infants with CF than in the healthy controls (-41 (-56--26) $\mathrm{mL})$. The prediction equations for RR, TPTEF:TE and FEV0.4 based on measurements from the 95 healthy infants are shown in table 3 .

SD scores were calculated from the following prediction equation:

(measured value-predicted value)/residual SD of the prediction (1)

Although statistically significant, the influence of length on the variability of TPTEF:TE was very small and only made a minimal contribution to the overall prediction model $\left(\mathrm{R}^{2}=0.079\right)$. Consequently, the unadjusted group mean and SD value for TPTEF:TE were used to calculate SD scores for this parameter. The relationship between SD scores for RR and TPTEF:TE and those for FEV0.4 are shown in figure 2. A total of 13 (28\%) infants with $\mathrm{CF}$ had a RR above the normal range (i.e. $>2 \mathrm{SD}$ ). In four of these, FEV0.4 was not obtained. In those where both parameters were obtained, there was no significant association between FEV0.4 and either RR $(\mathrm{p}=0.07)$ or TPTEF:TE ( $p=0.21$ ) when compared as SD scores (fig. 2).

\section{Discussion}

This study assessed tidal breathing parameters in infants newly diagnosed with $\mathrm{CF}$ and compared them with measurements from a large group of age-matched healthy infants. The relationship between these indices and measurements of FEV0.4 from the same infants was also examined, to assess whether the tidal breathing indices reflected differences in airway function between these two groups. After adjustment for body size, age, sex and exposure to maternal smoking, no differences in $V \mathrm{~T}$ or TPTEF:TE could be detected, and there was no relationship between TPTEF:TE and FEV0.4. MV was significantly increased in infants with $\mathrm{CF}$ due to an elevated RR, but no relationship could be identified between RR and FEV0.4.

Although of similar age when tested, the healthy infants were heavier and taller because of poorer growth in the infants with CF. For this particular study, a control group of

Table 3. - Prediction equations based on measurements from the healthy infants

\begin{tabular}{llcc}
\hline & Prediction & Residual & $\mathrm{R}^{2}$ \\
\hline RR min $^{-1}$ & $61.72-0.13$ (age weeks) -0.32 (length cm) & 5.61 & 0.40 \\
TPTEF:TE & $0.461-0.003$ (length cm) & 0.070 & 0.079 \\
FEV0.4 mL & $-304+7.53$ (length cm)+18.38 (female) & 41.4 & 0.64 \\
\hline
\end{tabular}

RR: respiratory rate; TPTEF:TE: tidal breathing ratio; FEV0.4: forced expiratory volume in 0.4 seconds. 

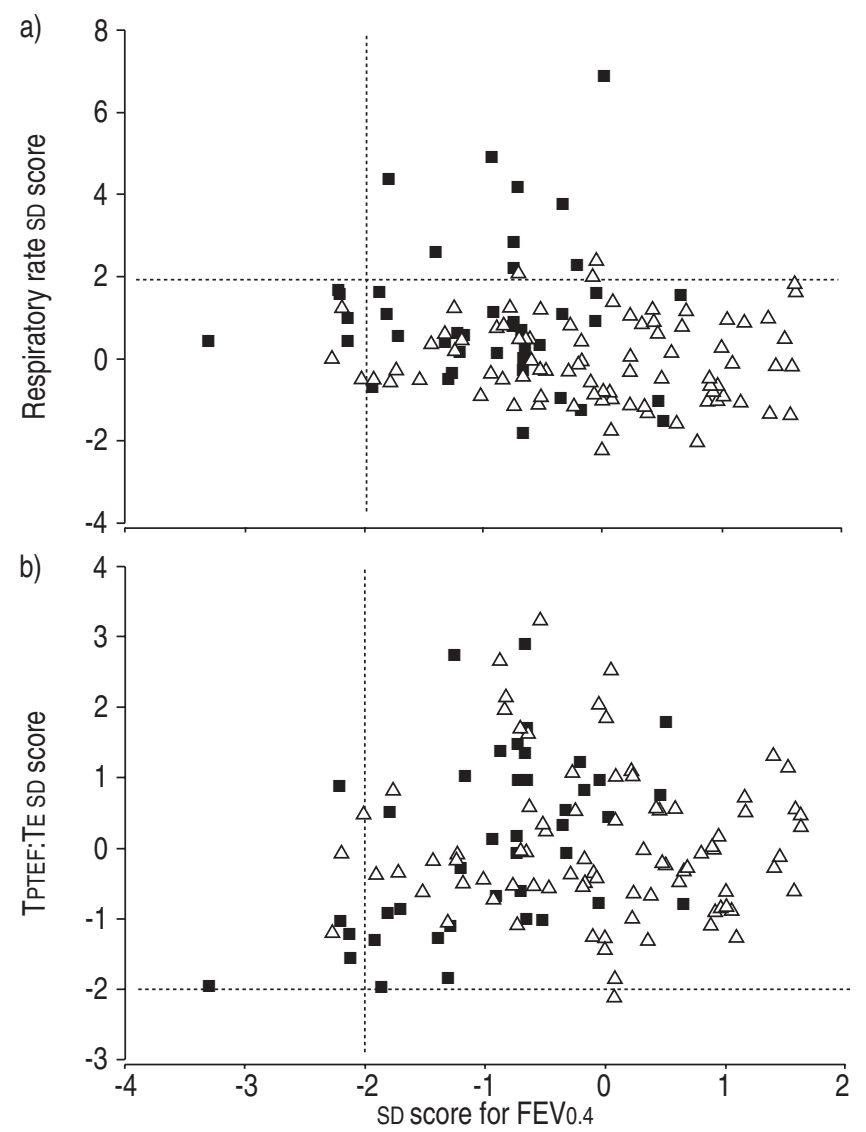

Fig. 2.-a) Respiratory rate and b) the tidal breathing ratio (TPTEF: TE) expressed as SD scores and plotted against SD score for forced expiratory volume in 0.4 seconds $\left(\mathrm{FEV}_{0.4}\right)$ according to disease status. : infants with cystic fibrosis; $\triangle$ : healthy infants. - - -: limits of normal (defined as \pm 2 SD).

similar age, rather than body size, was felt to be more appropriate, since tidal breathing parameters are considered to be age dependent [26], with a rapid fall in both RR and TPTEF:TE during the first few months of life [6, 27]. It is recognised that this may not be the case when comparing parameters of airway function that are highly dependent on body length [14, 15]. The authors addressed this potential problem by using multiple linear regression to account for differences in body size.

Tidal breathing indices can potentially be assessed during unsedated natural sleep, but this becomes more difficult with increasing postnatal age. Attempts were made in this study to measure RR prior to sedation using chest auscultation according to published guidelines [28]. However, accurate recordings of RR over a full minute proved difficult in awake and active infants. Sedation was used in this study as most of the infants were aged $>3$ months and the tidal breathing measurements preceded more complex forced expiratory manoeuvres. Furthermore, chloral hydrate or triclofos, in the doses commonly used for infant lung function tests, appear to have minimal effect on either TPTEF:TE [6] or RR [29, 30]. While poorer absorption of sedative could, theoretically, result in lighter sedation in infants with $\mathrm{CF}$, this is unlikely to have influenced the results of the current study, since no differences were observed between the two groups with respect to the duration of sleep induced by sedation and recordings were limited to periods of quiet sleep and regular tidal breathing.

TPTEF:TE was suggested by MORRIS and LANE [31] as a measure of airway obstruction in adults with chronic obstructive lung disease. Subsequent studies have demonstrated that a shortened ratio may also be associated with lower airway obstruction in children and infants. A significant, albeit weak, relationship has been observed between TPTEF:TE and forced expiratory volume in one second in subjects with $\mathrm{CF}$ aged 6-36 yrs [32]. Similarly, VAN DER ENT et al. [26] found that, amongst children aged 3-11 yrs, TPTEF:TE not only correlated with spirometric parameters, but increased following bronchodilator therapy in those with asthma. In the latter study, the ratio was also significantly lower in children with CF than in healthy subjects ( 0.27 versus 0.43 , respectively). However, results from infants have been somewhat conflicting. A reduced TPTEF:TE in early life has been observed in infants with a family history of asthma [33, 34] or whose mothers smoked during pregnancy [33, 35] and may be predictive of subsequent wheezing [4]. In addition, some authors have found a significant correlation between TPTEF:TE and maximal flow at functional residual capacity [8] and lower values in infants with chronic lung disease [36]. By contrast, other studies have found only a weak [7] or no relationship between TPTEF:TE and other parameters of lung function and have not been able to demonstrate any difference in TPTEF:TE between those with and without prior lower respiratory illness [37]. Indeed, it has been suggested that tidal breathing techniques do not reflect lung mechanics, but rather the dynamic, neuromuscular response of the infant to mechanical constraints imposed by lung disease [11].

To the authors knowledge, the current study is the first to investigate the ability of TPTEF:TE to identify diminished lung function in infants with CF. The values of TPTEF:TE in this study are similar to those previously reported in infants of a similar age [7, 26, 36]. However, the authors did not identify any differences between healthy infants and those with $\mathrm{CF}$ and therefore cannot recommend the use of this parameter as an outcome measure for future epidemiological or interventional studies involving infants with $\mathrm{CF}$.

In contrast to the lack of discrimination with respect to TPTEF:TE, RR was significantly greater in infants with CF after adjustment for known confounding factors. Despite the fact that these infants were tested when they were well and free from any acute exacerbation [38], three infants with CF had a RR $>60 \mathrm{~min}^{-1}$ which, when persistent, is one of the World Health Organisation criteria for the diagnosis of acute lower respiratory disease. Nevertheless, as shown in figure 2, there was considerable scatter between RR and FEV0.4, and the tendency for a negative association between the two did not quite reach statistical significance $(\mathrm{p}=0.07)$. In addition, all those with an elevated RR had FEV0.4 within the normal range, whereas RR was within the normal range in all those with diminished FEV0.4. This suggests that these parameters reflect different aspects of the early pathology of CF and that $\mathrm{RR}$ is influenced by factors other than airway obstruction or by airway properties that remain undetected by forced expiration in this age group. An increase in RR without any change in $V \mathrm{~T}$ has also been noted in adults with $\mathrm{CF}$ [39] where a significant correlation between RR and airway obstruction, arterial oxygenation and maximal ventilation during exercise suggested that an increase in RR is associated with severity of pulmonary disease in adults with CF. It is possible that the increased RR identified in infants with $\mathrm{CF}$ is related to other aspects of underlying pulmonary disease, particularly since it tended to be more elevated in those infants with clinical evidence of prior lower respiratory illness (fig. 3). However, while the increased RR could reflect the need to increase MV in the presence of impaired gas mixing or gas exchange, it could also be due to an increased metabolic rate, increased work of breathing and/or a higher surface area-to-weight ratio (because of failure to thrive). The use of more sophisticated techniques, such as multiple breath inert gas washout, which can also be performed during tidal breathing, but which give 


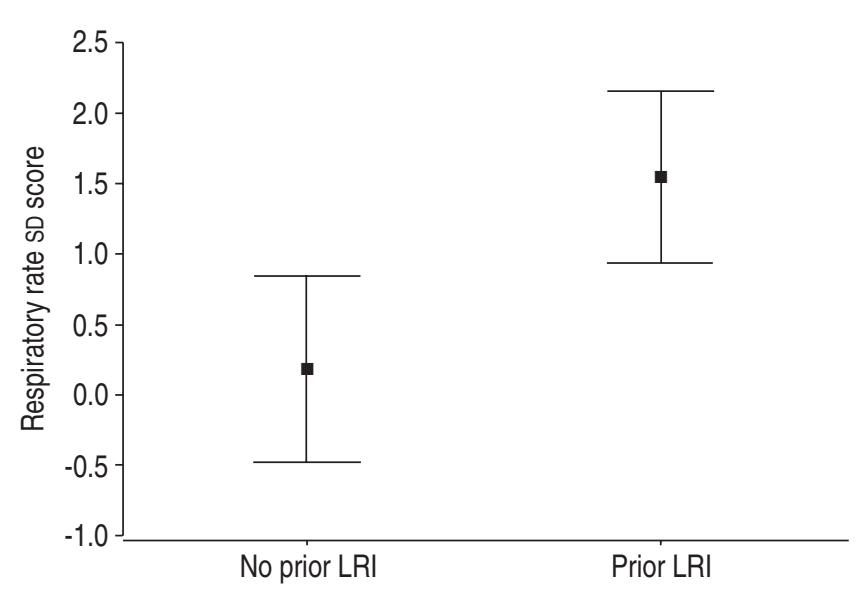

Fig. 3. - Respiratory rate SD score in infants with cystic fibrosis with (prior; $n=35$ ) and without (no prior; $n=12$ ) lower respiratory illness (LRI). The errors bars represent the $95 \%$ confidence interval of the mean SD score.

detailed information on ventilation distribution, could be used to evaluate the relative contribution of impaired gas mixing to alterations in RR in infants with CF [40].

In conclusion, the tidal breathing ratio does not appear to offer a useful objective means of identifying diminished airway function in infants newly diagnosed with cystic fibrosis when assessed during periods of clinical stability. Respiratory rate was significantly elevated in infants with cystic fibrosis, both as a group and in 13/47 (28\%) of individual infants, when compared with a prospectively measured healthy control group of similar age. Although this study shows that respiratory rate was poorly predictive of airway function, it is possible that an elevated respiratory rate is explained by other pathophysiological aspects of early pulmonary disease, such as impaired gas mixing, in infants with cystic fibrosis.

\footnotetext{
Acknowledgements. The authors would like to thank C. Dezateux for critical appraisal of this manuscript, A. Wade for advice regarding statistical analysis and the families who participated in this study.

The authors also wish to thank all members of the London Collaborative Cystic Fibrosis Group, which includes: B. Adler, I.B. Lynn, A. Bush, S. Carr, R. Castle, K. Costeloe, S. Davies, C. DamanWillems, J. Davies, C. Dezateux, R. Dinwiddie, J. Francis, I. Goetz, A.F. Hoo, J. Hawdon, S. Lum, S. Madge, J. Price, S. Ranganathan, M. Rosenthal, G. Ruiz, J. Stocks, J. Stroobant, A. Wade, C. Wallis, and $\mathrm{H}$. Wyatt.
}

\section{References}

1. Khan TZ, Wagener JS, Bost T, Martiniez J, Accurso FJ, Riches DWH. Early pulmonary inflammation in infants with cystic fibrosis. Am J Respir Crit Care Med 1995; 151: 10751082.

2. Gappa M, Ranganathan SC, Stocks J. Lung function testing in infants with cystic fibrosis: Lessons from the past and future directions. Pediatr Pulmonol 2001; 32: 228-245.

3. Martinez FD, Morgan WJ, Wright AL, Holberg CJ, Taussig LM. The Group Health Medical Associates' Personnel. Diminished lung function as a predisposing factor for wheezing respiratory illness in infants. N Engl J Med 1988; 319: 1112-1117.

4. Martinez FD, Morgan WJ, Wright AL, Holberg C, Taussig
LM. The Group Health Medical Associates. Initial airway function is a risk factor for recurrent wheezing respiratory illnesses during the first three years of life. Am Rev Respir Dis 1991; 143: 312-316.

5. Carlsen K-H, Lødrup-Carlsen KC. Tidal breathing analysis and response to salbutamol in awake young children with and without asthma. Eur Respir J 1994; 7: 2154-2159.

6. Stocks J, Dezateux CA, Jackson EA, Hoo A-F, Costeloe $\mathrm{KL}$, Wade AM. Analysis of tidal breathing parameters in infancy - How variable is tPTEF:tE? Am J Respir Crit Care Med 1994; 150: 1347-1354.

7. Dezateux CA, Stocks J, Dundas I, Jackson EA, Fletcher ME. The relationship between tPTEF:tE and specific airways conductance in infancy. Pediatr Pulmonol 1994; 18: 299-307.

8. Banovcin P, Seidenberg J, von der Hardt H. Assessment of tidal breathing patterns for monitoring of bronchial obstruction in infants. Pediatr Res 1995; 38: 218-220.

9. Bates J, Schmalisch G, Filbrun D, Stocks J. Tidal breath analysis for infant pulmonary function testing. Eur Respir $J$ 2000; 16: 1180-1192.

10. Lødrup KC, Mowinckel P, Carlsen KH. Lung function measurements in awake compared to sleeping newborn infants. Pediatr Pulmonol 1992; 12: 99-104.

11. Clarke J, Silverman M. Infant lung function and tidal breathing patterns. Pediatr Pulmonol 1995; 20: 135-136.

12. Rusconi F, Gagliardi L, Aston H, Silverman M. Changes in respiratory rate affect tidal expiratory flow indices in infants with airway obstruction. Pediatr Pulmonol 1996; 21: 236240.

13. Rosenstein BJ, Cutting GR. The diagnosis of cystic fibrosis: a consensus statement. J Pediatr 1998; 132: 589-595.

14. Ranganathan S, Dezateux CA, Bush A, et al. Airway function in infants newly diagnosed with cystic fibrosis. Lancet 2001; 358: 1964-1965.

15. Ranganathan SC, Bush A, Dezateux C, et al. Relative ability of full and partial forced expiratory maneuvers to identify diminished airway function in infants with Cystic Fibrosis. Am J Respir Crit Care Med 2002; 166: 1350-1357.

16. Lum S, Hoo AF, Dezateux C, Goetz I, et al. The association between birthweight, sex, and airway function in infants of nonsmoking mothers. Am J Respir Crit Care Med 2001; 164: 2078-2084.

17. Freeman JV, Cole TJ, Chinn S, Jones PRM, White EM, Preece MA. Cross sectional stature and weight reference curves for the UK, 1990. Arch Dis Child 1995; 73: 17-24.

18. Jarvis MJ, Tunstall-Pedoe H, Feyerabend C, Vesey C, Saloojee Y. Comparison of tests used to distinguish smokers from nonsmokers. Am J Public Health 1987; 77: 1435-1438.

19. Frey U, Stocks J, Coates A, Sly P, Bates J. Standards for infant respiratory function testing: Specifications for equipment used for infant pulmonary function testing. Eur Respir $J$ 2000; 16: 731-740.

20. Stocks J, Nothen U, Sutherland P, Hatch DJ, Helms P. Improved accuracy of the occlusion technique for assessing total respiratory compliance in infants. Pediatr Pulmonol 1987; 3: 1-77.

21. Prechtl HFR. The behavioural states of the newborn infant. Brain Res 1974; 76: 185-212.

22. Ranganathan SC, Hoo AF, Lum SY, Goetz I, Castle RA, Stocks J. Exploring the relationship between forced maximal flow at functional residual capacity and parameters of forced expiration from raised lung volume in healthy infants. Pediatr Pulmonol 2002; 33: 419-428.

23. Henschen M, Stocks J. Assessment of airway function using partial expiratory flow volume curves: How reliable is V'maxFRC during early infancy? Am J Respir Crit Care Med 1999; 159: 480-486.

24. American Thoracic Society. Standardization of spirometery 1994 update. Am J Respir Crit Care Med 1995; 152: 11071136.

25. Cohen J. Statistical power analysis for the behavioural 
sciences. 2nd edn. New Jersey, Lawrence Erlbaum Associates, 1988.

26. van der Ent CK, Brackel HJL, van der Laag J, Bogaard JM. Tidal breathing analysis as a measure of airway obstruction in children three years of age and older. Am J Respir Crit Care Med 1996; 153: 1253-1258.

27. Rusconi F, Castagneto M, Gagliardi L, et al. Reference values for respiratory rate in the first 3 years of life. Pediatrics 1994; 94: 350-355.

28. World Health Organisation. Programme for the control of acute respiratory infections. Geneva, World Health Organisation, 1990.

29. Rabbette PS, Dezateux CA, Fletcher ME, Costeloe KL, Stocks J. Influence of sedation on the Hering-Breuer Inflation Reflex in healthy infants. Pediatr Pulmonol 1991; 11: $217-222$

30. Jackson EA, Rabbette PS, Dezateux CA, Hatch DJ, Stocks J. The effect of triclofos sodium sedation on respiratory rate, oxygen saturation and heart rate in infants and young children. Pediatr Pulmonol 1991; 10: 40-45.

31. Morris MJ, Lane DJ. Tidal expiratory flow patterns in airflow obstruction. Thorax 1981; 36: 135-142.

32. Williams EM, Madgwick RG, Thomson AH, Morris MJ. Expiratory airflow patterns in children and adults with cystic fibrosis. Chest 2000; 117: 1078-1084.

33. Stick SM, Burton PR, Gurrin L, Sly PD, Le Souëf PN.
Effects of maternal smoking during pregnancy and a family history of asthma on respiratory function in newborn infants. Lancet 1996; 348: 1060-1064.

34. Dezateux C, Stocks J, Dundas I, Fletcher ME. Impaired airway function and wheezing in infancy. The influence of maternal smoking and a genetic predisposition to asthma. Am J Respir Crit Care Med 1999; 159: 403-410.

35. Hoo A-F, Henschen M, Dezateux CA, Costeloe KC, Stocks J. Respiratory function among preterm infants whose mothers smoked during pregnancy. Am J Respir Crit Care Med 1998; 158: 700-705.

36. Clarke JR, Aston H, Silverman M. Evaluation of a tidal expiratory flow index in healthy and diseased infants. Pediatr Pulmonol 1994; 17: 285-290.

37. Dezateux C, Stocks J, Wade AM, Dundas I, Fletcher ME. Airway function at one year: association with premorbid airway function, wheezing and maternal smoking. Thorax 2001; 56: 680-686.

38. Berman S, Simoes EA, Lanata C. Respiratory rate and pneumonia in infancy. Arch Dis Child 1991; 66: 81-84.

39. Browning IB, $\mathrm{D}^{\prime}$ Alonzo GE, Tobin MJ. Importance of respiratory rate as an indicator of respiratory dysfunction in patients with cystic fibrosis. Chest 1990; 97: 1317-1321.

40. Ljungberg H, Gustafsson P, Hulskamp G, Hoo A-F, Pillow J, Stocks J. Increased ventilation inhomogeneity in infants with Cystic Fibrosis. Eur Respir J 2002; 20: 209. 